\title{
A Socio-Technical Model for Project-Based Executive IT Governance
}

\author{
Kris Murphy \\ Case Western Reserve \\ University, \\ Cleveland, Ohio, United States \\ kam31@case.edu
}

\author{
Kalle Lyytinen \\ Case Western Reserve \\ University, \\ Cleveland, Ohio, United States \\ kj113@case.edu
}

\author{
Toni Somers \\ Wayne State University, \\ Detroit, MI, United States \\ toni_somers@wayne.edu
}

\begin{abstract}
Effectuating enterprise systems success through project-based, executive IT governance in the form of steering committees is a complex and multi-leveled challenge. Insight into the design of steering committees and what interrelated governance components are required is very limited. We propose a multi-leveled model to design effective steering committees. We develop this theoretical model and surmise that our project-based IT governance model offers more effective control. This proposition was developed using a sequential mixed-methods approach that combines qualitative and quantitative inquiry, and empirical research. We articulate a theoretical model informed by the punctuated sociotechnical change model, which synthesizes the dynamic capabilities and other components that influence steering committee performance. We find steering committees can achieve implementation success by balancing dynamic capabilities, structure, processes, and objectives. Contrary to common expectations, we learn that balanced, dynamic and agile steering committees are more effective than those that follow stale, procedural or routine approaches.

Keywords: IT governance; steering committee; information systems; IT governance board; fit; project success; project failure; capabilities; Enterprise Resource Planning; socio-technical change model
\end{abstract}

\section{Introduction}

Organizations typically deploy project-based IT governance in the form of a steering committee (SC) to oversee the implementation of large enterprisewide systems but often fail to deliver systems in time; and, functionality goals do not always meet user expectations. To be effective, an engaged SC should be more than a proverbial "checkbox" - something that is just required if a project over a certain dollar amount. If properly organized, SCs can become an integral component of large-scale systems implementations, if it succeeds in providing strategic direction, adequate monitoring and serves as a transformational change agent.

Academic and practitioner literature offer little in terms of how to design an engaged $\mathrm{SC}$ and how the design changes as the project progresses. Organizations are often left to sift through various practitioner guides and procedural checklists. Many guides suggest that having key executives (e.g. CEO, CIO, board members) on the committee will solve many problems. But is this the case? If an engaged $\mathrm{SC}$ is tasked to guide an enterprise-wide IT project, then resources that can process related information make the most sense. But, what operating model will the committee require to be successful? Will subcommittees be required?

Even when promising seamless integration of information across the organization and reduction of costs, and streamlined operations through the infusion of best business practices, organizations struggle to realize the benefits of enterprise systems. Successfully implementing these systems in a unified manner, under a unified technological umbrella, is a challenge. Globally, enterprise software is "to total $\$ 326$ billion, a 5.3 percent increase from 2015" (USD) [1 p. 1]. Despite years of practice and experience, there is very little return on investment when it comes to these implementations. SCs are tasked with guiding projects and making formal decisions but often undermine their effectiveness by post-decision debate. As pointed out by Scott McHale, Principal and Managing Director of the Hackett Group, "Once a decision is made continued vetting by $\mathrm{SC}$ members in hallway conversations often occurs, setting the tone that decisions weren't formally agreed to or final." Why do these problems exist and how can they be corrected?

While project teams tasked with delivering the desired functionality typically govern the implementation of such systems, executive oversight for such projects has evolved from allocating a single lead to creating diverse groups of knowledgeable 
executives that monitor and support the endeavor. Due to the complexity, size, and duration of these large IT implementations, the use of SCs has become common practice as organizations become more sophisticated. Organizations with sophisticated governance structures typically establish boundaryspanning committees that include representatives from all key functions and specialties impacted by the implementation. Few studies, discuss how engaged SCs are designed and navigate a project. A predominate portion of practitioner literature is anecdotal in nature, simply offering checklists and recommendations on who should serve on SCs.

\section{Theoretical Foundation}

The key theoretical underpinnings informing our study of SC performance in large-scale system implementations are broad categories of project structure, dynamic capabilities, processes and objectives that are informed by the punctuated sociotechnical change model [2, 3]. We develop our theoretical model, shown in Figure 1, based on sociotechnical theory $[2,3]$.

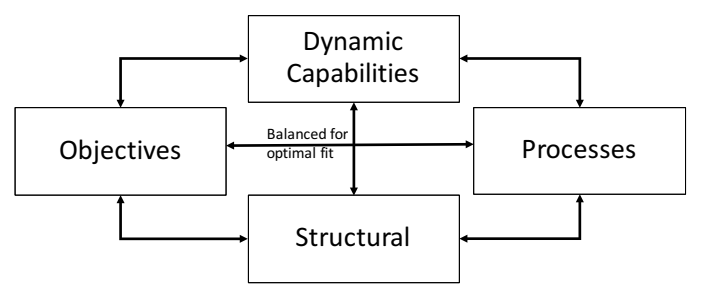

Figure 1. Theoretical Model

\subsection{Steering Committee}

SC (i.e., project-based, executive IT governance) use is typically considered a sound project management and its pivotal role is reinforced in the practitioner [4]. Our definition of a SC is informed by numerous studies as an ephemeral, autonomous boundary-spanning governance body consisting of senior level executives or boards who must possess dynamic capabilities in the form of decision-making, absorptive capacity, IS competence, and change leadership that are formed for a specific project [517]. These goal minded groups are associated with high-level IT sophistication and tend to have a multileveled impact on projects [13]. The literature suggests that SCs form an essential governance mechanism; therefore, their deployment is often viewed as a critical success factor during enterprise implementations [12, 18]. Yet, much current SC research has mainly focused on understanding its generic governance roles and related functions that support enterprise-wide IT planning and, to a degree, the related decision processes that focus on resource allocation $[12,18]$. Less is known about how SCs operate and what makes their work successful under different information processing conditions. As Lechler and Cohen [12] point out, there is a notable gap in understanding the inner workings of SCs.

Accordingly, we conducted a thorough review of $\mathrm{SC}$ literature. The review uses library searches on several academic search engines (including searches using EBSCO, IEEE Xplore, ABI/INFORM, First Search, and Google Scholar), reference databases, and 11 leading information systems journals including the 2011 AIS Senior Scholars' Basket of eight journals-i.e. Information Systems Journal, Journal of AIS, Journal of Information Technology, Journal of MIS, MIS Quarterly, European Journal of Information Systems, Journal of Strategic Information Systems and Information Systems Research-as well as Decision Sciences, Communications of the ACM, Information Systems and E-Businesses Management. We used the following keywords and phrases in our search: steering committee, IT governance board, project success, socio-technical change and critical success factors. Next, we conducted a multileveled analysis of the literature by not only reviewing each article but also reviewing their citations ("snow-balling"). Overall, the search did not result in a large number of SC studies consistent with earlier findings $[12,14]$.

We found a few substantive articles (practitioner and scholar) addressing SC functions, role, and performance. Most literature focuses on the relevance of SCs in an IT strategy context, as a means to balance a firm's IT portfolio. Most studies originate from practitioner literature which mainly offers normative discussions of SC functions by listing the committee's purpose (strategy, governance, planning, or portfolio), providing a sample of relevant participants, offering task guidelines, and stating some norms such as how frequently a committee should meet. Through this investigation, we find that a strong bias towards prescriptive practitioner guidance pervades the literature while there is limited or no explanatory understanding of what internal mechanisms exist, or how and why they work. Some formative research focuses on three primary questions: "Do companies use SCs? Why do companies have SCs? What do SCs do?" [14]. The literature suggests that having SCs is associated with having higher IT sophistication and more formalized project-based IT governance processes [5, 14]. Lechler and Cohen (2009) and other studies found that using a SC adds value, and the use of subcommittees was a common and effective tool [12, 13, 19]. Overall, studies on SCs offer limited explanations as to how this governance body can become successful, how it processes information, and 
what structural components it needs to achieve project success which we discuss next.

\subsection{Socio-Technical Model}

We employ Leavitt's socio-technical theory as a useful vehicle by which we can lay out the components of our governance model [2]. Leveraging Lyytinen and Newman's punctuated socio-technical change model we extend the underpinnings for our multi-level theoretical model and note the sociotechnical challenges of boundary-spanning which are "not ontologically fixed" [3 p. 594]. Our model consists of four balanced and interrelated components. These interconnected components are: 1) Objectives, 2) Structure, 3) Processes, and 4) Dynamic Capabilities. Component oneObjectives - encompasses the foundational aspects of a project, i.e. tasks, establishing timelines and projected deliverables. Component two-Dynamic Capabilities - encompasses autonomous processes such as change capabilities or enablers. Component three-Structural-relates to the SC, and how it exists in terms of size, levels of boundary-spanning executives. Component four-Processes-relates to actions taken by the governance body. The model maintains that each of the four components remain in balance to achieve a successful implementation. In alignment with Lyytinen and Newman (2008), each of the components can be decomposed to support the multi-leveled nature of an enterprise implementation [3]. We next discuss each of the components.

\subsection{Objectives}

This is the most foundational level of an ephemerality-based organization, the ideas and goals from the onset of the endeavor. At this level, objectives relate to the way the SC operates and the tasks it must perform which we draw from Leavitt's model. Objectives force the SC to adapt to the endeavor. These objectives usually include a certain level of uncertainty, complexity, and require set time and performance requirements to be carried out successfully[2, 20-23].

\subsection{Structure}

The structure of an organization includes the SC hierarchy, sub-committees, escalation path, size and communication systems. It is a delegating and boundary-spanning force. Structure includes membership expectations and common values and aligns with Leavitt's model. Structure also includes project structure; it also incorporates PM, communication, and workflow frameworks. Structure creates the foundation for governance of an enterprise implementation [2, 21-28].

\subsection{Processes}

Processes include the actions taken by the SC to complete and influence an organization's objectives. We deviate slightly from Leavitt's model since the primary actors are the members of the SC. Processes can influence the enterprise implementation, and it is imperative to align processes with organization objectives and structures to prevent being out-ofbalance which can result in project failure which is discussed in section $2.7[2,22,26,29,30]$.

\subsection{Dynamic Capabilities}

The SC must overcome unforeseen information processing needs by building information processing capabilities [14]. Accordingly, an enterprise project implementation requires high degrees of IT governance that can absorb and process IT information effectively through their stacked capabilities [11, 14]. Dynamic capabilities allow the SC to overcome uncertainty, steer the project and get the most out of the organization's technology investment. Dynamic capabilities are the enablers and are equivalent to Leavitt's technology component [2]. Today's complex systems force us to be more dynamic, think differently and have expectations of change that are not entirely clear.

\subsection{Balance and Fit}

The lack of fit between information processing needs and capability (i.e. gap or balance) can be significant during enterprise implementations, and it reduces the likelihood of project success, and certain types of failure start to emerge [31-35]. Fit is a theoretical construct which matches the SC's operating model against the information processing requirements and challenges of uncertainty of an enterprise project. Within this framework, fit is extrapolated to mean balance between the components to achieve the ultimate objective of having a successful project. If an unbalance situation occurs, the SC must adjust to meet the needs of the project. For example, a SC may be in the position to recalibrate the strategic goals of the project and better control expectations, thereby achieving more fit. Fundamentally, a SC needs to dynamically maintain information processing ability to balance the everchanging requirements of an enterprise implementation.

\section{Literature Gap}

The ubiquitous SC literature gap exists within the lack of analysis on what makes a SC operationally successful. Little is known about the operational structures within these groups and what challenges they must overcome. Many studies discuss 
the need to have executive leadership actively engaging in critical projects, but few discuss the best method on how to deploy key stakeholders and what capabilities they need. Within project-based executive IT governance in the form of SC literature, only two manuscripts discuss how operational value may be increased, one based on a qualitative study of 12 respondents and the second which discusses corporate board involvement in enterprise projects $[12,14,19]$.

From the available literature, we learn that to accomplish their tasks, SCs must garner enough capability to make sense and act upon a wide variety of design and implementation-related information. SC membership should encompass executives who can guide projects as a boundary-spanning unit. The operations and decisions of such committees must ensure that cross-functional alignment exists to support integrated platforms and a smooth implementation, resource constraints are recognized and overcome by proper resource allocation, and potential gaps in terms of software or process obstacles are removed. As a strategic liaison, the SC needs to bridge the gap between IT leadership and general management. We argue that SCs can achieve project success through manipulation of the four components of our socio-technical governance model to achieve project success. We define project success as strategic alignment and "the extent to which the project meets its technical goals, remains within the budget, and is delivered in time" which are dimensions of project success that SCs can influence [11: 4, 36]. Additionally, meeting technical goals is understood broadly to mean that the enterprise software is configured to meet the users' functional requirements, system outputs function as expected, and performance is adequate-quality exists. Based on this definition and the previously noted challenges, we developed the aforementioned theoretical framework for SCs.

\section{Research Questions}

The four specific research questions that guide the research are:

1. What factors contribute to the performance of enterprise system steering committees in implementing successful enterprise-wide technology solutions? What challenges do steering committees face?

2. Which capabilities influence how a steering committee achieves project success?

3. What antecedents accentuate steering committee capability and positively influence project success?

4. Is a steering committee an agent of change?

\section{Methodology}

The study follows a sequential, mixed-method approach that combines qualitative and quantitative inquiry. Using a grounded theory approach, we first conduct semi-structured ethnographic interviews among a theoretical sample of experienced SC team members. Then, we deploy a survey to collect data for the quantitative studies.

In this section, we review the research methodology proposed for the overall study. We followed a QUAL $\rightarrow$ QUAN $\rightarrow$ QUAN $\rightarrow$ QUAN mixed-methods approach in an exploratory sequential design [37]. Since there are no preexisting studies in this area, we required an exploratory study from which we grounded our overall study. Hence, we adopt a qualitative grounded theory approach to gain an understanding of the factors that influence steering committee success and the challenges these governance bodies face. The second study builds upon the findings of the first study by using a quantitative approach and structural equation model to measure the findings. The third and fourth studies use a quantitative approach and leverage the significant findings gathered in the first and second studies. Then, we triangulate the findings from all four studies and look to the literature to draw a comprehensive set of findings before recommending a framework to practitioners. The generative design follows these steps:

Study 1: Identify the theoretical framework and factors that influence SC outcomes (qualitative study).

Study 2: Validate the theoretical framework through a field study by identifying the capabilities that are required.

Study 3: Extend the theoretical framework and investigate how certain factors can accentuate capabilities.

Study 4: Extend the theoretical framework and investigate how certain socio-technical factors can increase user satisfaction.

\subsection{Qualitative Study}

As previously discussed, we conducted an openended qualitative study to understand internal dynamics of SCs. Lacking theories and mechanisms from which to begin our study, we sought to discern what makes SCs effective, and we conducted research across a myriad of industries for variously sized organizations. The evaluation of SC performance was conducted at an individual level to elicit actual experiences that these groups witnessed throughout numerous implementations. Thirty phenomenological, semi-structured interviews 
informed by grounded theory principles of Strauss and Corbin [38], were conducted with executives that served on SCs. Each executive was asked open-ended and semi-structured questions as to their experience on successful and unsuccessful committees for which they served. Our data was interpreted using analytical methods recommended by Strauss and Corbin [38] that included constant comparison and theoretical sampling. Emergent themes and concepts are directed towards forward samplings, which continued until no more themes or concepts could be identified, signaling theoretical saturation.

\subsection{Quantitative Studies}

We conduct three quantitative studies using the themes and findings from study one. We create a theoretical model, and survey 164 steering committees using a psychometric methodology that maps individual responses to the underlying constructs. Using Qualtrics, we collected data over a three-month period that terminated in January 2015. SCs are comprised of senior managers who oversee the implementation of an ERP. We leveraged alumni networks of a large systems integrator and two universities to capture survey responses. We also used IS researchers, LinkedIn Recruiter, and select executives from our personal network. Only candidates with leadership profiles were emailed (e.g. project manager, program manager, program director, IT director, VP, CAO, CIO, CFO, CRO, CEO, COO, CTO, senior manager, senior director or leadership).

Since few constructs have ever been operationalized and used in the context of a SC, care was taken to develop reliable and valid measures following the procedures suggested by DeVellis [39]. Items selected for the constructs were adapted from prior studies to facilitate content validity. We conducted several rounds of pre-testing using concurrent verbal protocol content analysis [40]. As a result, many items were modified slightly to address problems with comprehension and judgment.

\section{Data Analysis}

The hypothesized relationships among constructs were analyzed using partial least squares algorithm (PLS) and SmartPLS application version 3.2.3. The decision to use PLS, rather than a covariance-based structured equation model (SEM), was based primarily on the nature of the study-formative construct and limited sample size. We conducted an exploratory factor analysis (EFA) and confirmatory factor analysis (CFA) for each study. Most items loaded on their respective factors with values greater than 0.50. These factors were the minimum conservative value for practical significance as well as in cases where the threshold was not met the items were removed. Cronbach's alphas were above the 0.70 threshold [41]. The significance of parameters was assessed using asymptotic t-statistics generated by resampling techniques in which we tested using 5,000 subsamples [41]. We tested for CMB by comparing standardized regression weights of factor loadings with and without an embedded marker variable [42]. We tested convergent validity of the factors using three tests recommended by Fornell and Larker: item reliability, composite reliability and average variance extracted (AVE). All items demonstrated standardized loadings on their respective factors greater than 0.50 , demonstrating item reliability [41]. Composite reliability for all reflective factors was greater than 0.70 , indicating internal consistency [41]. AVE was greater than 0.50 for all factors, the minimum threshold [41]. Mediation effects were checked using a product-ofcoefficients and the methods outlined by MacKinnon et al. [43](i.e., Sobel test).

\subsection{Quantitative Study One}

Our model involved seven constructs and four controls, all of which were measured with reflective scales, except uncertainty, which was a formative construct. This formative construct was created using inputs from two reflective scales. The structural model for QUAN 1 is shown below.

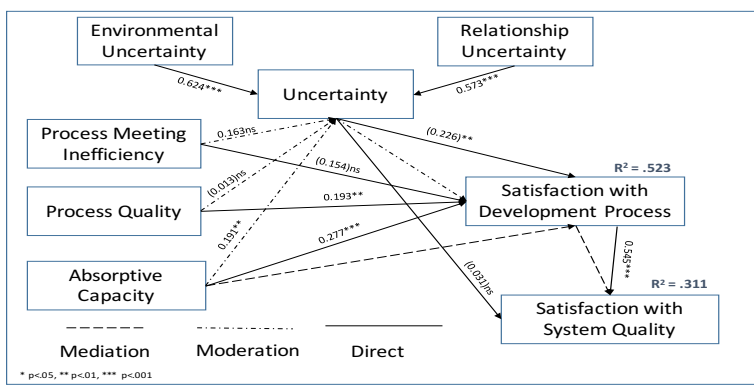

Figure 2. QUAN 1 Structural Model

\subsection{Quantitative Study Two}

Leveraging the results from the first quantitative study, our second quantitative study modeled eight constructs and two controls, all of which were measured with reflective scales. The structural model for QUAN 2 is shown below.

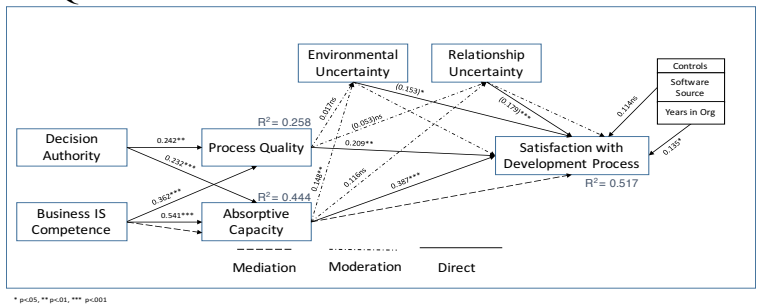




\section{Figure 3. QUAN 2 Structural Model}

\subsection{Quantitative Study Three}

Leveraging the results from the first two quantitative study, our third quantitative study modeled five constructs and two controls, all of which were measured with reflective scales. The structural model for QUAN 3 is shown below. Next, we discuss the data collection and methodological approach.

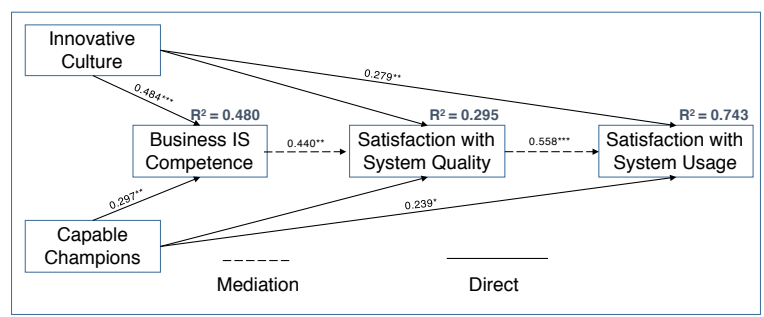

Figure 4. QUAN 3 Structural Model

\subsection{Sample Size and Data Collection}

For the qualitative study, we interviewed participants of 30 successful and 30 unsuccessful steering committees. All quantitative studies shared 164 survey responses. The qualitative study used the primary researcher's network for data collection discussed previously.

\subsection{Integrated Findings}

In this section, we discuss the integrated findings that are most relevant to form an operating model for SCs. We base these findings on thoughtful analysis of each study in our four-part sequence. After discussing the integrated results, we then discuss the key findings that emerged from the individual studies. The results of all four studies were triangulated to synthesize five major findings which promote a SC's capability in achieving implementation success. We find that SC must have clear common goals, objectives and roles. Allowing members to make critical decisions, equipping them with dynamic capabilities of business IS competence, and selecting members with absorptive capacity impacts almost every other factor that predicts implementation success. We found that a SC must be designed rather than elected with each member having a distinct role and appropriate capabilities. We found that having agility is paramount and that a SC brings the most value during project phase transitions, critical decision points and not necessarily by meeting regularly - insightfulness over being routine. Agility can mean frequency of meetings and dynamics in terms of structure once a
SC transitions from its strategic role to monitoring. We also found that a SC should maintain a distinct role difference from that of a project team. A summary of the integrated findings and the research questions they address is provided in Table 1.

Table 1. Integrated Findings

\begin{tabular}{|c|c|c|}
\hline$\#$ & Integrated Finding & $\begin{array}{c}\text { Research } \\
\text { Questions } \\
\text { Addressed }\end{array}$ \\
\hline Finding 1 & $\begin{array}{c}\text { Decision authority and autonomy promote } \\
\text { better decision processes }\end{array}$ & Q1, Q3 \\
\hline Finding 2 & $\begin{array}{c}\text { SC design is critical and member } \\
\text { selection needs to be a well-thought } \\
\text { process }\end{array}$ & Q1, Q2, Q3, Q4 \\
\hline Finding 3 & $\begin{array}{c}\text { SCs need to be agile in nature and meet } \\
\text { when critical issues arise }\end{array}$ & Q1, Q2 \\
\hline Finding 4 & $\begin{array}{c}\text { SCs that do not have the necessary skills } \\
\text { are prone to failure }\end{array}$ & Q1, Q2, Q3, Q4 \\
\hline Finding 5 & SCs are an agent of change & Q1, Q4 \\
\hline
\end{tabular}

\subsection{Qualitative study findings}

We identified that Galbraith's information processing view theory helps us understand how these SCs process information through capability. We find that when a lack of fit exists, SCs struggled to achieve success. On the other hand, we find that when a SC increases capability, success is more achievable. For instance, it was not uncommon to find the usage of sub-committees (regional or functional) to assist with processing information. The detailed themes and findings for this study are listed in Tables 2 .

Table 2. QUAL Themes and Findings

\begin{tabular}{|l|l|}
\hline \multicolumn{1}{|c|}{$\#$} & \multicolumn{1}{c|}{ Finding } \\
\hline Finding 1 & Steering committee performance is impacted through a multileveled grouping of factors. \\
\hline Finding 2 & $\begin{array}{l}\text { There is no evidence that steering committees need to meet more often than when critical } \\
\text { decisions are required or the project reaches a critical transition point. Meeting when } \\
\text { there is no information to process adds no value to the project. }\end{array}$ \\
\hline Finding 3 & $\begin{array}{l}\text { Smaller firms may not require steering committees because use of these committees may } \\
\text { place too great a burden on the organization. }\end{array}$ \\
\hline Finding 4 & Steering committees function better when there is a defined decision maker. \\
\hline Finding 5 & $\begin{array}{l}\text { Complex interdependencies and uncertainties between factors have a causal affect and } \\
\text { often leave steering committees grappling with their ability to process information. We } \\
\text { found common usage of sub or "working" committees to process information. }\end{array}$ \\
\hline Finding 6 & Steering committee performance is impacted through a multileveled grouping of factors. \\
\hline
\end{tabular}

\subsection{Quantitative Study 1 findings:}

Building on the qualitative study, we found that committee process quality contributes to project success as committee time is better allocated to pivotal tasks. Secondly, uncertainty negatively effects implementation success, and the level of uncertainty negatively moderates the positive impact of a SC's absorptive capacity. Surprisingly, we did not find substantial evidence that a SC with inefficient meeting practices has a negative effect on project success. We found that it is more important to be absorptive. Nevertheless, we hold that there is 
enough statistical support to suggest that having efficient and organized procedures would not harm the project outcome.

Table 3. QUAN 1 Findings

\begin{tabular}{|l|c|}
\hline Hypotheses & Supported? \\
\hline $\begin{array}{l}\text { H1: SC Process Meeting Inefficiency is negatively related to Satisfaction with the } \\
\text { Development Process. }\end{array}$ & Tentatively \\
\hline $\begin{array}{l}\text { H2: Steering Committee Process Quality is positively related to Satisfaction with the } \\
\text { Development Process. }\end{array}$ & Yes \\
\hline $\begin{array}{l}\text { H3: Absorptive Capacity is positively related to Satisfaction with the Development } \\
\text { Process. }\end{array}$ & Yes \\
\hline H4: Uncertainty is negatively related to Satisfaction with the Development Process. & Yes \\
\hline H5: Uncertainty is negatively related to Satisfaction with System Quality. & No \\
\hline $\begin{array}{l}\text { H6a: Uncertainty positively moderates the negative relationship of Process Meeting } \\
\text { Inefficiency on Satisfaction with the Development Process. }\end{array}$ & No \\
\hline $\begin{array}{l}\text { H6b: Uncertainty negatively moderates the positive relationship of Process Meeting } \\
\text { Quality on Satisfaction with the Development Process. }\end{array}$ & No \\
\hline $\begin{array}{l}\text { H6c: Uncertainty negatively moderates the positive relationship of Absorptive } \\
\text { Capacity with Satisfaction with the Development Process. }\end{array}$ & Yes \\
\hline $\begin{array}{l}\text { H7a: Satisfaction with the Development Process mediates the relationships between } \\
\text { Uncertainty and Satisfaction with System Quality. }\end{array}$ & No \\
\hline $\begin{array}{l}\text { H7b: Satisfaction with the Development Process mediates the relationships between SC } \\
\text { Process Meeting Inefficiency and Satisfaction with System Quality. }\end{array}$ & No \\
\hline $\begin{array}{l}\text { H7c: Satisfaction with the Development Process mediates the relationships between SC } \\
\text { Process Quality and Satisfaction with System Quality. }\end{array}$ & Yes \\
\hline $\begin{array}{l}\text { H7d: Satisfaction with the Development Process mediates the relationships between } \\
\text { Absorptive Capacity and Satisfaction with System Quality. }\end{array}$ & Yes \\
\hline
\end{tabular}

\subsection{Quantitative Study 2 findings}

Expanding the first quantitative study, we utilize the model from study two that identified the SC constructs of absorptive capacity and process quality as the core capabilities that predict project success. Then, we drop the non-significant process inefficiency factor and look for antecedents which bolster these capabilities. We extend our analysis to include the indirect effects of business IS competence and decision authority on the core capability factors of project success. We found that both decision authority and business IS competence are dynamic supporting capabilities that play a significant role in the success of a SC. With these powerful and dynamic antecedents, a SC's core capabilities are strengthened. Consequently, project success effects are greater.

Table 4. QUAN 2 Findings

\begin{tabular}{|c|c|c|}
\hline \# & Hypothesis Test & $\begin{array}{l}\text { Supported } \\
(\text { Yes } / \mathrm{No})\end{array}$ \\
\hline$H I$ & Decision Authority is positively related to Process Quality. & Yes \\
\hline $\mathrm{H}_{2}$ & Decision Authority is positively related to Absorptive Capacity. & Yes \\
\hline$H 3$ & Business IS Competence is positively related to Process Quality. & Yes \\
\hline $\mathrm{H} 4$ & Business IS Competence is positively related to Absorptive Capacity. & Yes \\
\hline $\mathrm{H} 5$ & Process Quality is positively related to Satisfaction with the Development Process. & Yes \\
\hline H6 & $\begin{array}{l}\text { Absorptive Capacity is positively related to Satisfaction with the Development } \\
\text { Process. }\end{array}$ & Yes \\
\hline H7 & Uncertainty is negatively related to Satisfaction with the Development Process. & Yes \\
\hline$H 7 a$ & $\begin{array}{l}\text { Environmental uncertainty is negatively related to Satisfaction with the } \\
\text { Development Process. }\end{array}$ & Yes \\
\hline$H 7 b$ & $\begin{array}{l}\text { Relationship uncertainty is negatively related to Satisfaction with the Development } \\
\text { Process. }\end{array}$ & Yes \\
\hline H8 & $\begin{array}{l}\text { Uncertainty negatively moderates the positive relationship between Process Quality } \\
\text { and Satisfaction with the Development Process. }\end{array}$ & No \\
\hline H8a & $\begin{array}{l}\text { Environmental Uncertainty negatively moderates the positive relationship between } \\
\text { Process Quality and Satisfaction with the Development Process. }\end{array}$ & No \\
\hline $\mathrm{H} 8 \mathrm{~b}$ & $\begin{array}{l}\text { Relationship Uncertainty negatively moderates the positive relationship between } \\
\text { Process Quality and Satisfaction with the Development Process. }\end{array}$ & No \\
\hline $\mathrm{H} 9$ & $\begin{array}{l}\text { Uncertainty negatively moderates the positive relationship between Absorptive } \\
\text { Capacity and Satisfaction with the Development Process. }\end{array}$ & Partially \\
\hline$H 9 a$ & $\begin{array}{l}\text { Environmental Uncertainty negatively moderates the positive relationship between } \\
\text { Absorptive Capacity and Satisfaction with the Development Process. }\end{array}$ & Yes \\
\hline $\mathrm{H} 9 \mathrm{~b}$ & $\begin{array}{l}\text { Relationship Uncertainty negatively moderates the positive relationship between } \\
\text { Absorptive Capacity and Satisfaction with the Development Process. }\end{array}$ & No \\
\hline$H 10$ & $\begin{array}{l}\text { Absorptive Capacity fully mediates the positive relationship between Business IS } \\
\text { Competence and Satisfaction with the Development Process. }\end{array}$ & Yes \\
\hline$H I I$ & $\begin{array}{l}\text { Satisfaction with the development process fully mediates the positive relationship } \\
\text { between Absorptive Capacity and Satisfaction with System Quality. }\end{array}$ & Yes \\
\hline
\end{tabular}

\subsection{Quantitative Study 3 findings}

Expanding the two quantitative studies, we utilize dynamic capabilities of business IS competence (BISC) and satisfaction with system quality (SSQ) to ground our study of the two sociotechnical factors of innovative culture (IC) and capable champions (CC) and the impact on satisfaction with system usage (SSU). We found that a SC plays a socio-technical role in an enterprise implementation.

Table 5. QUAN 3 Findings

\begin{tabular}{|l|l|l|}
\hline$\#$ & Hypothesis Test & $\begin{array}{l}\text { Support } \\
\text { (Yes/No) }\end{array}$ \\
\hline 1 & IC is positively related to BISC & Yes \\
\hline 2 & CC is positively related to BISC & Yes \\
\hline $3 \mathrm{a}$ & $\begin{array}{l}\text { BISC positively mediates the relationships between IC and } \\
\text { SSQ }\end{array}$ & Yes \\
\hline $3 \mathrm{~b}$ & $\begin{array}{l}\text { BISC positively mediates the relationships between CC and } \\
\text { SSQ }\end{array}$ & Yes \\
\hline 4 & IC is positively related to SSQ & No \\
\hline 5 & CC is positively related to SSQ & No \\
\hline $6 \mathrm{a}$ & $\begin{array}{l}\text { SSQ positively mediates the relationships between IC and } \\
\text { SSU }\end{array}$ & No \\
\hline $6 \mathrm{~b}$ & $\begin{array}{l}\text { SSQ positively mediates the relationships between CC and } \\
\text { SSU }\end{array}$ & No \\
\hline $6 \mathrm{c}$ & $\begin{array}{l}\text { SSQ positively mediates the relationships between BISC and } \\
\text { SSU }\end{array}$ & Yes \\
\hline 7 & IC is positively related to SSU & Yes \\
\hline 8 & CC is positively related to SSU & Yes \\
\hline
\end{tabular}

\section{A Project-Based Socio-Technical Executive Governance Model}

Our sequential study identified multiple factors that a SC utilizes to overcome uncertainty and complexity while delivering successful projects. Using this sequential study method, we learned what components were required at the inception of a project and through each remaining phase, which allows us to develop an initial framework for designing a SC. We began by leveraging our sequential studies, board and project team research to understand what elements were required to design a $\mathrm{SC}$. We feel that there are four key elements to a successful SC design: foundational, structural, composition, and process. These elements transcend the three levels of a project: control, project team and end-users.

The foundational element helps us understand the project dynamics in terms of complexity, risk, duration, and multi-levelness and leverages aspects of the Lyytinen and Newman's socio-technical change model which explains information systems change across levels and events [3]. The structural elements include the size, sub-committees, subject matter experts, defined decision-makers, level of stewardship, and independence required for a SC to perform its tasks. We posit that governance boards should have less than 10 members, with the caveat that complementing units will extend capability by pre-processing decision information. The 
composition element include experience, skills, level of autonomy, decision authority, business IS competence, innovative culture, capable champions and absorptive capacity. Our theoretical model is balanced and includes a mapping of the factors from all four studies into each component (shown in Figure 5). These four components must remain in balance for a SC to steer a complex enterprise project. Each component depends on the other similar to the punctuated socio-technical change model: objectives (e.g. goals, tasks) define the enabling capabilities that are required for the project, the structure must support the processes and tasks otherwise a gap will result, capabilities must support processes for a SC to complete its objectives [3].

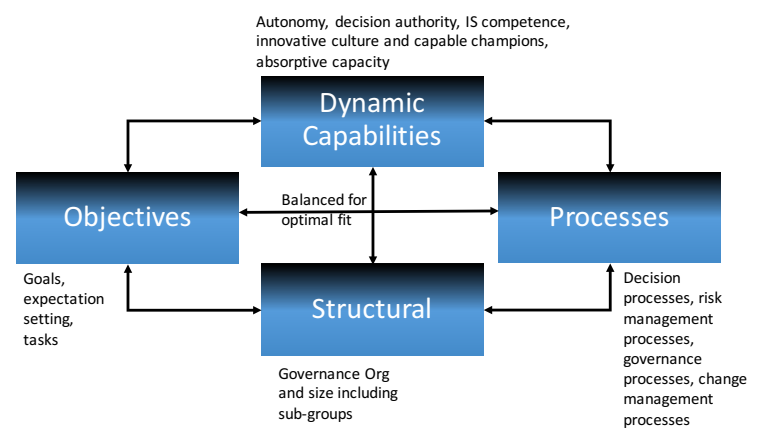

Figure 5. Socio-Technical Executive Governance Model

\section{Discussion}

Before this sequential study, there was a dearth of understanding about steering committees and their influencing antecedents. Beyond anecdotal practitioner guidelines, no framework exists which is based on research and an empirical literature review. Our studies on steering committees and project success paved the way for this proposition by emphasizing the need for this research [44]. Since steering committees are complex, we looked to relevant control research, how they approach project success, how they interact with organizations, and how they process information. We found that SCs require agility and a complex and interrelated set of dynamic capabilities to achieve project success. Each of the core capabilities of SC process quality and absorptive capacity, require powerful antecedents of decision authority and business IS competence to increase effectiveness. We also identified that SC design should consider factors such as size, member selection-to-recruitment ratio, transparency of roles relative to those of the project team and adequate risk structures.

Immediately, we noticed that the gap in literature extended to research on what makes steering committees operational and successful in terms of project outcomes. We knew, as the current literature explains, that SCs must possess certain capabilities to comprehend and carry out a multitude of implementation information. We then used this literature and a developed theoretical framework to conduct a mixed-method research plan, one consisting of one qualitative study and two quantitative studies. We knew that we needed to understand the internal construction of a steering committee; thus, we implemented our QUAL study. Our two QUANT studies, then, were used to conduct surveys of practitioners with seasoned leadership roles, and analyze the received data.

Based on the outcome of our three sequential studies we offer a SC design framework that organizations can leverage to build their committees. SC design should be based on careful considerations of the skills required to execute each dynamic capability. SC recruitment should be a well thought out process, and be similar to those of corporate boards that have formal recruitment processes. SCs need to build information processing capacity that allows them to overcome project complexity and empower project teams to succeed.

This research has profound implications for practice that can be measured in many ways. First, it explains that certain SC roles exist because of the need for absorptive capacity. It also helps managers understand what requisite skills are required for SC members to effectively oversee an enterprise project. The research also exposes certain components of uncertainty that have a negative effect on system implementation, which are not so obvious. Practitioners should take note in advance of undertaking projects to ensure that proper risk management exists for the type of uncertainty they may encounter. For example, projects with high environmental risk will require a SC that not only has business IS competence but a high degree of absorptive capacity. Practitioners should consider vertical and horizontal expansion by using subcommittees to accommodate complex information processing needs. Practitioners can leverage our framework to design their SC for projects that are multi-leveled and boundary-spanning in nature. The SC design framework (SCDF) allows the practitioner to be better prepared and add sophistication to their project-based, IT governance structures.

\section{Contributions to Theory}

The study contributes to SC and IS leadership theory in multiple ways. First, this research is one of the first significant academic works focusing on the internal mechanisms influencing a SC's performance. Second, this study identifies multiple components through which a SC can effectively steer successful 
large enterprise-wide projects. Third, this research introduces notions of socio-technical factors and risk to the domain of executive project-based IT governance. Fourth, this research offers a new model through which a SC can be designed by extending the principles established for other governance boards and change models.

\section{Lessons for Practice}

Preparing SCs for complex IS projects is not a simple, routine job, nor is it a task where selection is simply based on a title. Organizations need to prepare adequately and give careful consideration to which members are assigned to a SC and which members have which powers. This study has only grasped the surface, and notable gaps exist within project-based executive level IT governance literature. Practitioner literature may offer interesting checklists, but success will require a well-designed committee that contains people with dynamic capabilities and is naturally agile.

\section{References}

[1] Gartner, "Gartner Says Worldwide It Spending Is Forecast to Grow 0.6 Percent in 2016", Gartner Press Release, 2016,

[2] Leavitt, H.J., "Applied Organisation Change in Industry: Structural, Technical and Human Approaches", New Perspectives in Organisational Research, John Wiley, 1964 ,

[3] Lyytinen, K., and Newman, M., "Explaining Information Systems Change: A Punctuated SocioTechnical Change Model", European Journal of Information Systems, 17(6), 2008, pp. 589-613.

[4] Kerzner, H.R., Project Management: A Systems Approach to Planning, Scheduling, and Controlling, Wiley, 2013.

[5] Doll, W.J., and Torkzadeh, G., "The Relationship of Mis Steering Committees to Size of Firm and

Formalization of Mis Planning", Communications of the ACM, 30(11), 1987, pp. 972-978.

[6] Farris, J.A., "An Empirical Investigation of Kaizen Event Effectiveness: Outcomes and Critical Success Factors", 2006,

[7] Hobbs, B., and Ménard, P., "Organizational Choices for Project Management", The AMA Handbook of Project Management, 1993, pp. 81-108.

[8] Karimi, J., Bhattacherjee, A., Gupta, Y.P., and Somers, T.M., "The Effects of Mis Steering Committees on Information Technology Management Sophistication",
Journal of Management Information Systems, 17(2), 2000, pp. 207-230.

[9] Kerzner, H., Advanced Project Management: Best Practices on Implementation, John Wiley \& Sons, 2004.

[10] Margolis, J., and Donnellon, A., "Mod Iv Product Development Team", Harvard Business School case study, 1990, pp. 9-491.

[11] Fisk, A., Berente, N., and Lyytinen, K., "Boundary Spanning Competencies and Information System Development Project Success", in (Editor, 'ed.'^'eds.'): Book Boundary Spanning Competencies and Information System Development Project Success, 2010, pp. 96.

[12] Lechler, T.G., and Cohen, M., "Exploring the Role of Steering Committees in Realizing Value from Project Management", Project management journal, 40(1), 2009, pp. 42-54.

[13] Murphy, K., Boland, R., "Enterprise Software Solutions: How Do Steering Committees Steer?", in (Editor, 'ed.'^'eds.'): Book Enterprise Software Solutions: How Do Steering Committees Steer?, DSI, Tampa, FL, 2014

[14] Murphy, K., A Theory of Steering Committee Capabilities for Implementing Large Scale Enterprise-Wide Information Systems, Case Western Reserve University, 2016.

[15] Murphy, K., Lyytinen, K., and Somers, A., "A Theory of Steering Committee Capabilities for Implementing Enterprise-Wide Information Systems", in (Editor, 'ed.'^'eds.'): Book A Theory of Steering Committee Capabilities for Implementing Enterprise-Wide Information Systems, Academy of Management, 2016, pp. 11741.

[16] Murphy, K., Lyytinen, K., and Somers, T., "Does Steering Committee Information Processing Capacity Influence Project Success in Enterprise-Wide System Implementations", in (Editor, 'ed.'^'eds.'): Book Does Steering Committee Information Processing Capacity Influence Project Success in Enterprise-Wide System Implementations, IEEE, 2016, pp. 4942-4951.

[17] Murphy, K., Lyytinen, K., and Somers, T., "How Can Steering Committees Manage Change through Dynamic Capabilities to Increase System Satisfaction?", in (Editor, 'ed.'^'eds.'): Book How Can Steering Committees Manage Change through Dynamic Capabilities to Increase System Satisfaction?, 2017

[18] Somers, T.M., and Nelson, K.G., "The Impact of Critical Success Factors across the Stages of Enterprise Resource Planning Implementations", in (Editor, 'ed.'^'eds.'): Book The Impact of Critical Success Factors across the Stages of Enterprise Resource Planning Implementations, IEEE, 2001, pp. 10 pp. 
[19] Jewer, J., and Mckay, K.N., "Antecedents and Consequences of Board It Governance: Institutional and Strategic Choice Perspectives", Journal of the Association for Information Systems, 13(7), 2012, pp. 581.

[20] Lucas, H.C., "Alternative Structures for the Management of Information Processing", On the Economics of Information Processing, 2(1982, pp. 55-61.

[21] Lyytinen, K., "Different Perspectives on Information Systems: Problems and Solutions", ACM Computing Surveys (CSUR), 19(1), 1987, pp. 5-46.

[22] Curtis, B., Krasner, H., and Iscoe, N., "A Field Study of the Software Design Process for Large Systems", Communications of the ACM, 31(11), 1988, pp. 12681287.

[23] Nidumolu, S., "The Effect of Coordination and Uncertainty on Software Project Performance: Residual Performance Risk as an Intervening Variable", Information systems research, 6(3), 1995, pp. 191-219.

[24] Ouchi, W.G., "A Conceptual Framework for the Design of Organizational Control Mechanisms": Readings in Accounting for Management Control, Springer, 1979, pp. $63-82$.

[25] Ouchi, W.G., and Price, R.L., "Hierarchies, Clans, and Theory Z: A New Perspective on Organization Development", Organizational Dynamics, 7(2), 1978, pp. 25-44.

[26] Perrow, C., "Complex Organizations: A Critical Essay, 2nd Edn (Scott, Foresman)", 1979,

[27] Damanpour, F., "Organizational Innovation: A MetaAnalysis of Effects of Determinants and Moderators", Academy of Management Journal, 34(3), 1991, pp. 555590.

[28] Beath, C.M., "Managing the User Relationship Im Information Systems Development Projects: A Transaction Governance Approach", in (Editor, 'ed.'^'eds.'): Book Managing the User Relationship Im Information Systems Development Projects: A Transaction Governance Approach, 1987, pp. 20.

[29] Ginzberg, M.J., "Early Diagnosis of Mis Implementation Failure: Promising Results and Unanswered Questions", Management science, 27(4), 1981, pp. 459-478.

[30] Willcocks, L., and Margetts, H., "Risk and Information Systems: Developing the Analysis": Information Management, Springer, 1994, pp. 207-230.

[31] Premkumar, G., Ramamurthy, K., and Saunders, C.S., "Information Processing View of Organizations: An Exploratory Examination of Fit in the Context of
Interorganizational Relationships", Journal of Management Information Systems, 22(1), 2003, pp. 257-294.

[32] Venkatraman, N., and Camillus, J.C., "Exploring the Concept of "Fit" in Strategic Management", Academy of management review, 9(3), 1984, pp. 513-525.

[33] Lyytinen, K., and Hirschheim, R., "Information Systems Failures: A Survey and Classification of the Empirical Literature", Oxford surveys in information technology, 4(1), 1987, pp. 257-309.

[34] Galbraith, J.R., "Organization Design: An Information Processing View", Interfaces, 4(3), 1974, pp. 28-36.

[35] Lyytinen, K., and Robey, D., "Learning Failure in Information Systems Development", Information Systems Journal, 9(2), 1999, pp. 85-101.

[36] Delone, W.H., "The Delone and Mclean Model of Information Systems Success: A Ten-Year Update", Journal of Management Information Systems, 19(4), 2003, pp. 9-30.

[37] Clark, V.L.P., and Creswell, J.W., "Designing and Conducting Mixed Methods Research", in (Editor, 'ed.'^'eds.'): Book Designing and Conducting Mixed Methods Research, Thousand Oaks, CA: Sage, 2011

[38] Strauss, A., and Corbin, J., Basics of Qualitative Research, Sage Publications, 2nd edn, 1990.

[39] Devellis, R.F., Scale Development: Theory and Applications, Sage Publications, Inc, 2011.

[40] Bolton, R.N., "Pretesting Questionnaires: Content Analyses of Respondents' Concurrent Verbal Protocols", Marketing Science, 12(3), 1993, pp. 280-303.

[41] Hair, J., Black, W., Babin, B., Anderson, R., and Tatham, R., "Multivariate Data Analysis. A Global Perspective", in (Editor, 'ed.'^'eds.'): Book Multivariate Data Analysis. A Global Perspective, Pearson Prentice Hall, 2010

[42] Podsakoff, P.M., Mackenzie, S.B., Lee, J.-Y., and Podsakoff, N.P., "Common Method Biases in Behavioral Research: A Critical Review of the Literature and Recommended Remedies", Journal of applied psychology, 88(5), 2003, pp. 879.

[43] Mackinnon, D.P., Fritz, M.S., Williams, J., and Lockwood, C.M., "Distribution of the Product Confidence Limits for the Indirect Effect: Program Prodclin", Behavior research methods, 39(3), 2007, pp. 384-389.

[44] Murphy, K.L., Kalle; Somers, Toni, "Does Steering Committee Information Processing Capacity Influence Project Success in Enterprise-Wide System Implementations", 2016, pp. 4942-4951. 